\title{
Investigating critical thinking skills practices in Qatari Elementary Schools
}

\begin{abstract}
The purpose of this study was to examine how government and independent elementary school teachers in Qatar compare on promoting students' critical thinking skills in the classroom. A total of 441 participants completed a 30-item, critical thinking skills questionnaire based on Bloom's taxonomy of educational objectives cognitive domain, which aimed at assessing teachers' frequency of using certain critical thinking activities in the context of classroom instruction. Multivariate analysis of variance procedure indicated significant differences on the application, analysis, synthesis, and evaluation levels, but not on knowledge and comprehension. No significant differences were observed between the government and independent school teachers based on years of teaching experience. These results are discussed in light of their implications for the undergoing education reform in Qatar. (C) Common Ground, Yassir Semmar, Aisha Fakro, All Rights Reserved.
\end{abstract}

